\title{
The Effects of Caffeine on Sleep in Drosophila Require PKA Activity, But Not the Adenosine Receptor
}

\author{
Mark N. Wu, ${ }^{1 *}$ Karen Ho, ${ }^{2 *}$ Amanda Crocker, ${ }^{2}$ Zhifeng Yue, ${ }^{3}$ Kyunghee Koh, ${ }^{2}$ and Amita Sehgal ${ }^{2,3}$ \\ ${ }^{1}$ Division of Sleep Medicine, Department of Neurology, ${ }^{2}$ Department of Neuroscience, and ${ }^{3}$ Howard Hughes Medical Institute, University of Pennsylvania, \\ Philadelphia, Pennsylvania 19104
}

\begin{abstract}
Caffeine is one of the most widely consumed stimulants in the world and has been proposed to promote wakefulness by antagonizing function of the adenosine $\mathrm{A}_{2 \mathrm{~A}}$ receptor. Here, we show that chronic administration of caffeine reduces and fragments sleep in Drosophila and also lengthens circadian period. To identify the mechanisms underlying these effects of caffeine, we first generated mutants of the only known adenosine receptor in flies $(d A d o R)$, which by sequence is most similar to the mammalian $\mathrm{A}_{2 \mathrm{~A}}$ receptor. Mutants lacking dAdoR have normal amounts of baseline sleep, as well as normal homeostatic responses to sleep deprivation. Surprisingly, these mutants respond normally to caffeine. On the other hand, the effects of caffeine on sleep and circadian rhythms are mimicked by a potent phosphodiesterase inhibitor, IBMX (3-isobutyl-1-methylxanthine). Using in vivo fluorescence resonance energy transfer imaging, we find that caffeine induces widespread increase in cAMP levels throughout the brain. Finally, the effects of caffeine on sleep are blocked in flies that have reduced neuronal PKA activity. We suggest that chronic administration of caffeine promotes wakefulness in Drosophila, at least in part, by inhibiting cAMP phosphodiesterase activity.
\end{abstract}

\section{Introduction}

Caffeine is one of the most commonly used psychoactive substances and has been shown to antagonize adenosine receptor signaling, inhibit cAMP phosphodiesterase (PDE) activity, and activate ryanodine receptors. However, the promotion of wakefulness by caffeine is widely thought to be mediated by its antagonism of adenosine receptors, based on its higher affinity for these molecules (Fredholm et al., 1999).

In addition to its connection to caffeine, adenosine itself is strongly implicated in sleep regulation, as a sleep-promoting factor (Radulovacki et al., 1984; Rainnie et al., 1994; Basheer et al., 2004). Microdialysis experiments demonstrate that increased sleep drive is accompanied by an increase in endogenous adenosine levels locally in the basal forebrain and in the cortex (PorkkaHeiskanen et al., 1997). There are four adenosine receptors in mammals: $A_{1}, A_{2 A}, A_{2 B}$, and $A_{3} . A_{1}$ and $A_{2 A}$ receptors are enriched in the nervous system, while the others are expressed diffusely at low levels (Landolt, 2008). Administration of $\mathrm{A}_{1}$ and $\mathrm{A}_{2 \mathrm{~A}}$ receptor agonists promotes sleep (Benington et al., 1995; Portas

\footnotetext{
Received April 6, 2009; revised July 22, 2009; accepted July 23, 2009.

M.N.W. is supported by a Career Award for Medical Scientists Award from the Burroughs-Wellcome Foundation and National Institute of Neurological Disorders and Stroke Grant K08NS059671. K.H. was supported by a Pickwick Fellowship from the National Sleep Foundation. K.K. is supported by National Institutes of Health (NIH) Grant P01AG017628. A.S. is supported by NIH Grants R01NS048471 and P01AG017628 and is an Investigator of the Howard Hughes Medical Institute. We thank H. Keshishian, R. Davis, J. Kiger, and P. Taghert for fly lines. We thankW Joiner for comments and for outcrossing lines and the Sehgal laboratory for helpful discussions. We thank H. Su for providing the original $d A d O R$ CDNA clone.

${ }^{*}$ M.N.W. and K.H. contributed equally to this work.

Correspondence should be addressed to Amita Sehgal, Department of Neuroscience/University of Pennsylvania,

232 Stemmler Hall, 3450 Hamilton Walk, Philadelphia, PA 19104. E-mail: amita@mail.med.upenn.edu.

M. N. Wu's present address: Department of Neurology, Johns Hopkins University, Baltimore, MD 21287.

DOI:10.1523/JNEUROSCI.1653-09.2009

Copyright $\odot 2009$ Society for Neuroscience $\quad$ 0270-6474/09/2911029-09\$15.00/0
}

et al., 1997; Methippara et al., 2005), whereas knockdown of the $A_{1}$ receptor using antisense oligonucleotides reduces baseline sleep and impairs homeostatic regulation of sleep (Thakkar et al., 2003).

Despite these findings, there is little genetic evidence indicating an essential role for adenosine receptors in the regulation of sleep. Mouse knock outs of the $\mathrm{A}_{1}$ or $\mathrm{A}_{2 \mathrm{~A}}$ receptor have no alterations of baseline sleep amount (Stenberg et al., 2003; Huang et al., 2005). In addition, $A_{1}$ knock-out mice have no defects in the homeostatic regulation of sleep (Stenberg et al., 2003), and nor are there any published data demonstrating such defects for $A_{2 \mathrm{~A}}$ knock-out mice. However, $A_{2 A}$ knock-out mice do appear to be insensitive to the wake-promoting effects of acute caffeine injection (Huang et al., 2005). Recently, mice with targeted deletion of the $\mathrm{A}_{1}$ receptor in CAMKII+ cells were described. These mice do not show significant changes in amount of total or slow wave sleep, but do exhibit decreased slow-wave activity (SWA) power at baseline and following sleep deprivation (Bjorness et al., 2009). Finally, recent data suggest that eliminating adenosine accumulation in the basal forebrain of rats has no effect on sleep rebound or delta power following sleep deprivation (Blanco-Centurion et al., 2006). Together, these findings suggest that despite the strong evidence implicating adenosine in sleep regulation, further experiments, particularly in vivo genetic analyses, may be helpful in evaluating this hypothesis.

Here, we demonstrate that chronic administration of caffeine reduces and fragments sleep in Drosophila and also lengthens circadian period. Similar effects on sleep and circadian period are observed when flies are fed isobutylmethylxanthine (IBMX), a nonspecific phosphodiesterase inhibitor. Surprisingly, these effects of caffeine on sleep and circadian rhythms are not mediated by the single adenosine receptor identified in flies. Instead, we 
find widespread elevations of cAMP levels in the fly brain with caffeine treatment and show that the effects of caffeine on sleep require PKA activity. We propose that in Drosophila the mechanisms underlying wake-promoting effects of chronic caffeine administration involve enhanced cAMP/PKA signaling.

\section{Materials and Methods}

Fly stocks. Fly stocks were raised at $23^{\circ} \mathrm{C}$ on standard cornmeal-molasses medium. The wild-type caffeine sensitive strain RC1 (\#3865), KG03964 (\#13273), and Df(3R)Exel6214 (\#7692), and elav-Gal4 C155 (\#458) were obtained from the Bloomington Stock Center (Bloomington, IN). All lines used for behavioral analysis in this study were outcrossed at least $5 \times$ into the RC1 background. The P-insertion line KG03964 was mobilized to generate $d A d o R$, which bears a 4562 bp deletion removing the entire $d A d o R$ open reading frame (ORF). For the $d A d o R$ mutant, sibling controls were established after outcrossing $5 \times$ into the $R C 1$ background. elav-GS was provided by H. Keshishian (Yale University, New Haven, CT), MB-GS by R. Davis (Baylor College of Medicine, Houston, TX), UAS-PKAR by J. Kiger (UC Davis, Davis, CA), and UAS-Epac1-camps by P. Taghert (Washington University, St. Louis, MO).

Molecular biology. A partial dAdoR (CG9753) cDNA was obtained by RTPCR. The remaining $3^{\prime}$ end of the $d A d o R$ ORF was isolated using PCR from a BAC clone containing the region (RH38494, Invitrogen), using the following primers: forward primer-5' CTGTTCCAAATCCCGTTC and reverse primer-5' CAAGGTACCGAAGGTCAACTCTCCG and subsequently confirmed by sequencing. An in-frame fusion of GFP to the C-terminal end of $d A d o R$ was created by PCR of the same $3^{\prime} d A d o R$ fragment, with the STOP codon mutated to Gly using the primer reverse-5' CAGGTACCCGAAGGTCCACTCTCCG. For expression of dAdoR-GFP in S2 cells, the dAdoR-GFP cDNA was subcloned into the pAC-V5-HisA vector. Quantitative real-time PCR was performed essentially as previously described (Zheng et al., 2007).

Cell culture assays and Western blotting. dAdoR-GFP was transfected into S2 cells using Cellfectin (Invitrogen) according to manufacturer's protocol. A stably expressing $d A d o R-G F P$ cell was selected by individual cell-sorting based on GFP fluorescence intensity. This line was used in all subsequent cell culture experiments, with the original S2 line passaged in tandem used as the control. MAPK phosphorylation in response to $3 \mu \mathrm{M}$ adenosine (Sigma) was measured using anti-MAPK and anti-P-MAPK antibodies (Sigma). Expression of dAdoR-GFP protein in S2 cells was confirmed by Western blotting of transfected cell extracts using anti-GFP and anti-V5 antibodies (Invitrogen) and ECL (Pierce). The ratio of phosphorylated versus total MAPK was measured by digital densitometry using a Kodak 440 CF Image Station with Kodak 1D software (Kodak).

Behavioral assays. Sleep and circadian behavior were measured using Drosophila Activity Monitoring Systems (Trikinetics) in 5\% sucrose/2\% agarose glass tubes maintained in a well humidified incubator (Thermo Scientific) at $25^{\circ} \mathrm{C}$. Sleep was identified as a minimum of $5 \mathrm{~min}$ of locomotor inactivity as described previously (Andretic and Shaw, 2005; Ho and Sehgal, 2005). Sleep data were collected in $1 \mathrm{~min}$ bins and analyzed using a sliding window with custom-designed MATLAB software (MathWorks). Circadian data were analyzed using Clocklab (Actimetrics Software). Unless otherwise specified, flies used in behavioral experiments were pre-entrained for $2 \mathrm{~d}$ in a $12 / 12 \mathrm{~h}$ light/dark (L/D) cycle. Flies were 5-8-d-old at the start of the behavioral experiments.

For measurements of baseline sleep phenotypes, data were recorded for $2 \mathrm{~d}$ in a 12/12 L/D cycle and averaged. For circadian measurements, activity was recorded for $6 \mathrm{~d}$ in constant darkness (DD). For caffeine treatment, flies (after pre-entrainment) were transferred to 5\% sucrose $/ 2 \%$ agarose tubes containing either no caffeine or caffeine (ranging from 0.1 to $0.5 \mathrm{mg} / \mathrm{ml}$ ) (Sigma) at the subjective light-onset time (CT0) in DD. For IBMX (Sigma), flies were treated as for caffeine treatment, except they were fed IBMX in doses ranging from 0.025 to $0.1 \mathrm{mg} / \mathrm{ml}$ in $1 \% \mathrm{EtOH})$, and corresponding control flies were fed $1 \% \mathrm{EtOH}$. For CPT (8-cyclopentyll-1,3-dimethylxanthine) and DMPX (3,7-dimethyl-1propargylxanthine) (Sigma), flies were treated as for caffeine, except that $0.6 \mathrm{mg} / \mathrm{ml}$ and $0.3 \mathrm{mg} / \mathrm{ml}$ doses were used respectively, and drugs were solubilized by adjusting $\mathrm{pH}$. Arousal threshold experiments were per-
A
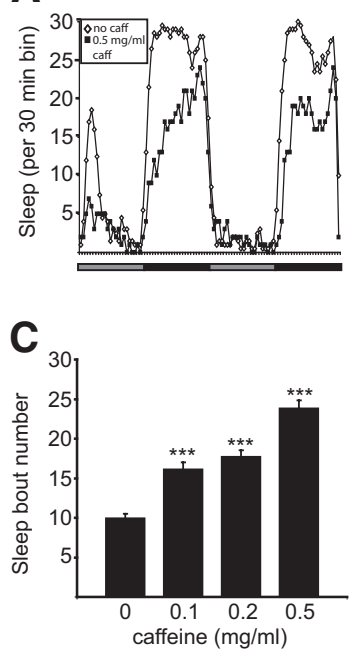

E

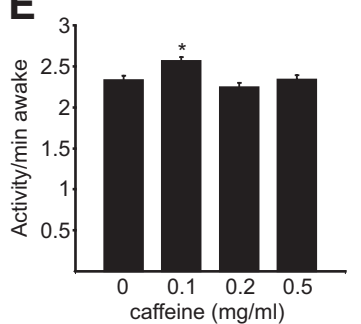

B

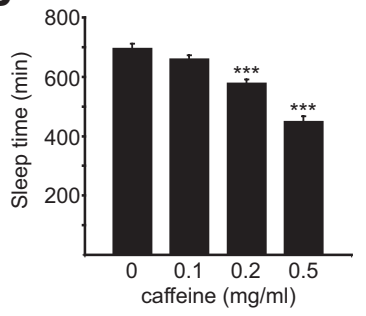

D

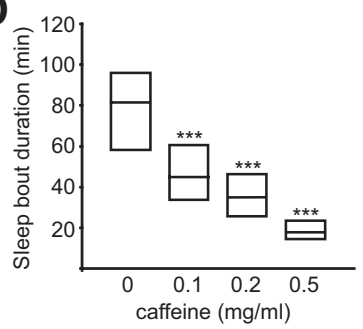

$\mathbf{F}$

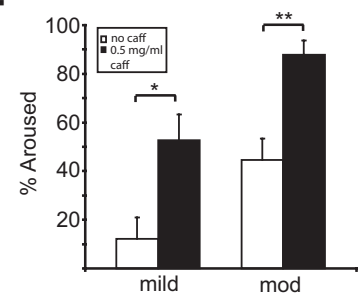

Figure 1. Effects of caffeine on sleep and arousal on wild-type $R C 1$ flies. A, Sleep profile plotted in $30 \mathrm{~min}$ bins for female flies fed no caffeine (open diamonds) or $0.5 \mathrm{mg} / \mathrm{ml}$ caffeine (closed squares). Gray bars and black bars represent subjective day and night, respectively. $\boldsymbol{B}$, Daily sleep time for female flies fed $0(n=64), 0.1(n=63), 0.2(n=63)$, or $0.5(n=64)$ $\mathrm{mg} / \mathrm{ml}$ caffeine. In this and subsequent figures, error bars represent SEM. $C-E$, Daily sleep bout number $(\boldsymbol{C}$, daily sleep bout duration $(\boldsymbol{D})$, and waking activity $(\boldsymbol{E})$ for female flies fed $0,0.1,0.2$, or $0.5 \mathrm{mg} / \mathrm{ml}$ caffeine. In $\boldsymbol{D}$, sleep bout duration, which is not normally distributed, is presented as simplified box plots. The line inside each box indicates the median, and the top and bottom represent 75 th and 25 th percentiles, respectively. Similar boxplots are shown for all subsequent plots of sleep bout duration. $\boldsymbol{F}$, Arousal threshold measurements for female flies fed no caffeine (white bars) or $0.5 \mathrm{mg} / \mathrm{ml}$ caffeine (black bars), in response to a mild ("mild") or a moderate ("mod") mechanical stimulus. For mild stimulus, $n=109$ for no caffeine and $n=99$ for caffeine-fed, and for moderate stimulus, $n=112$ for no caffeine and $n=93$ for caffeine-fed. ${ }^{*} p<0.05,{ }^{* *} p<0.01,{ }^{* * *} p<0.001$, compared with the no-caffeine group. Data from the same flies are shown from $\boldsymbol{A}-\boldsymbol{E}$. caff, Caffeine.

formed essentially as described (Wu et al., 2008), except that only mild and moderate stimuli were used.

For rebound experiments using mechanical deprivation, flies were deprived of sleep from ZT18-24 as previously described, and only animals whose sleep was decreased by at least $70 \%$ over the $6 \mathrm{~h}$ period were included in the analysis (Wu et al., 2008). Sleep latency was defined as time after ZT0 following deprivation until the first bout of sleep.

For RU486 induction of elav-Geneswitch and MB-Geneswitch drivers, flies were fed $0.5 \mathrm{~mm}$ RU486 in 1\% EtOH as diluent (Sigma) for $2 \mathrm{~d}$ in $5 \%$ sucrose $/ 2 \%$ agarose tubes, and then transferred into $5 \%$ sucrose $/ 2 \%$ agarose tubes containing either no caffeine or caffeine $(0.5 \mathrm{mg} / \mathrm{ml})$. For uninduced controls, flies were fed $1 \% \mathrm{EtOH}$ alone.

Fluorescent resonance energy transfer imaging of cAMP levels. Brains from elav-Gal4/+; UAS-Epac1-camps (50A)/+ (Shafer et al., 2008) flies were dissected in ice-cold calcium-free saline containing $46 \mathrm{~mm} \mathrm{NaCl}$, $180 \mathrm{~mm} \mathrm{KCl}$, and $10 \mathrm{~mm}$ Tris, $\mathrm{pH}$ 7.2. The brains were then laid at the bottom of a $35 \times 10 \mathrm{~mm}$ plastic FALCON Petri dish (Becton Dickenson Labware), given a few seconds to adhere and then covered with $1.6 \mathrm{ml}$ of hemolymph-like saline (HL3) containing $70 \mathrm{~mm} \mathrm{NaCl}, 5 \mathrm{~mm} \mathrm{KCl}, 1.5 \mathrm{~mm}$ $\mathrm{CaCl}_{2}, 20 \mathrm{~mm} \mathrm{MgCl}_{2}, 10 \mathrm{~mm} \mathrm{NaHCO} 3,5 \mathrm{~mm}$ trehalose, $115 \mathrm{~mm}$ sucrose, and 5 mM HEPES, pH 7.1 (Shafer et al., 2008). 
A

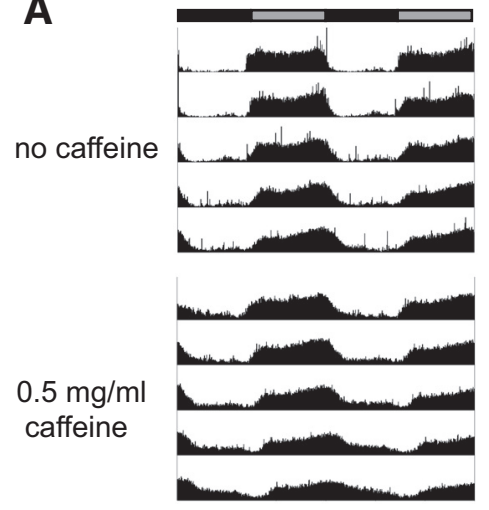

B

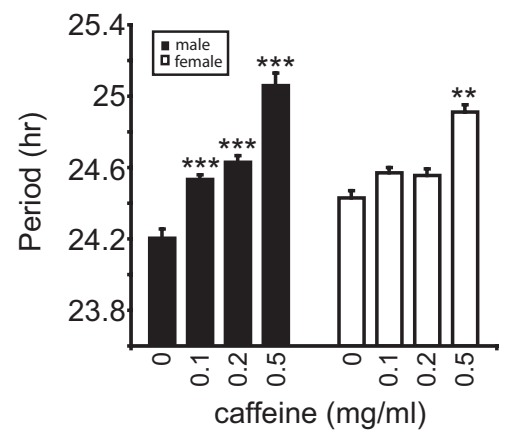

Figure 2. Effects of caffeine on circadian period. $A$, Average activity profiles are shown for female flies fed no caffeine or 0.5 $\mathrm{mg} / \mathrm{ml}$ caffeine. Gray bars and black bars represent subjective day and night, respectively. $\boldsymbol{B}$, Period (in hours) for flies fed 0 ( $n=$ 62 for males, $n=64$ for females), 0.1 ( $n=61, n=63), 0.2(n=62, n=64)$, or $0.5(n=34, n=63) \mathrm{mg} / \mathrm{ml}$ caffeine. Black bars denote male flies and white bars denote female flies. ${ }^{* *} p<0.01$, ${ }^{* * *} p<0.001$, compared with the no-caffeine group.

Time course fluorescent resonance energy transfer (FRET) imaging of pan-neuronally expressed Epac1-camps was performed on individual brains using a Leica TCS SP5 confocal microscope using a HCX APO L $40 \times / 0.80$ dipping objective. $60 \mu \mathrm{l}$ of $10 \mathrm{mg} / \mathrm{ml}$ caffeine was added into the dish for a final concentration of $0.375 \mathrm{mg} / \mathrm{ml}$ following $3 \mathrm{~min}$ of baseline imaging. In the water control, $60 \mu \mathrm{l}$ of water was added. To quantify yellow fluorescent protein (YFP) $(525 \mathrm{~nm}) /$ cyan fluorescent protein (CFP) $(475 \mathrm{~nm})$ peak values, spectral analysis was used, taking images from $470 \mathrm{~nm}$ to 599 $\mathrm{nm}$ in $10 \mathrm{~nm}$ increments at $256 \times 256$ pixels, $700 \mathrm{~Hz}$, and a line average of two every $20 \mathrm{~s}$. Regions of interest (ROIs) on the brains were selected and examined for changes in YFP/CFP peak height value on the spectral analysis.

Statistical analysis. For comparisons of two genotypes or doses, unpaired $t$ tests with unequal variances were used, except for analysis of sleep bout duration (which is not normally distributed), where Mann-Whitney $U$ test was used. For comparisons of more than two genotypes or doses, one-way ANOVAs with genotype or dose as a between-subject factor were used, and if there was a significant effect, post hoc comparisons with Tukey honestly significant differences (HSD) were performed. For analysis of dose-dependent caffeine responses in control versus $d A d o R$ flies, two factor ANOVAs were performed using genotype and caffeine doses as between-subject factors and, if there was a significant main effect, post hoc comparisons with Tukey HSD were performed. For analysis of FRET signals for different regions of interest, ANOVAs were performed on data pooled in $6 \mathrm{~min}$ bins, and post hoc comparisons with Tukey HSD were performed. Statistical analyses were performed using STATISTICA (StatSoft).

D
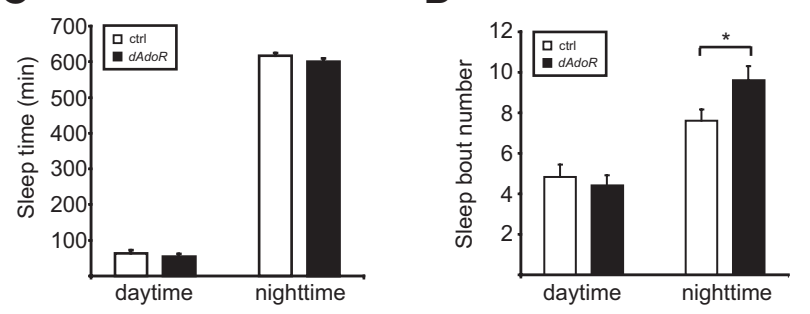

E

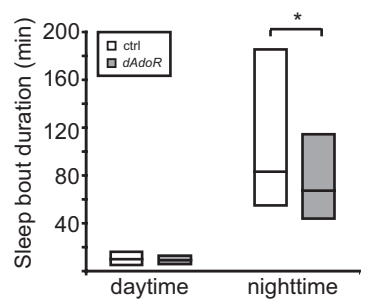

Figure 3. The Drosophila adenosine receptor ( $(A A d o R)$ is not required for baseline sleep regulation. $\boldsymbol{A}$, Ratio of phosphorylated MAP kinase (P-MAPK) to unphosphorylated MAP kinase (MAPK) from S2 cells for the following: untransfected cells without adenosine (closed diamond, dashed line), untransfected cells treated with $3 \mu \mathrm{m}$ adenosine (open square, dashed line), $d A d o R$-transfected cells without adenosine (closed diamond, solid line), or dAdoR-transfected cells with $3 \mu$ m adenosine (open square, solid line). This experiment was performed three times with similar results. $\boldsymbol{B}$, Levels of $d A d o R$ transcript as measured by real-time $P C R$ and normalized to actin levels for control and $d A d o R$ mutant fly heads $(H)$ and bodies $(B) .{ }^{*} p<0.05$ for control heads versus bodies. ${ }^{* * *} p<0.001$ for control compared with $d A d o R$. C, Daytime and nighttime sleep in $\mathrm{L} / \mathrm{D}$ for control $(n=64)$ and $d A d o R$ mutant $(n=64)$ female flies. $\boldsymbol{D}, \boldsymbol{E}$, Daily sleep bout number $(\boldsymbol{D})$ and daily sleep bout duration $(\boldsymbol{E})$ for control and $d A d o R$ female flies. For $\boldsymbol{C}-\boldsymbol{E}$, controls are denoted by white bars and $d A d o R$ mutants with dark bars. ${ }^{*} p<0.05$ for sleep bout duration for $d A d o R$ vs controls. Data from the same flies are shown for $\mathbf{C}-\boldsymbol{E}$. ctrl, Control.

\section{Results}

Caffeine reduces sleep and lengthens period in Drosophila

As in mammals, acute caffeine administration in Drosophila $(0.25-5.0 \mathrm{mg} / \mathrm{ml}$ over $8-12 \mathrm{~h})$ reduces sleep time (Hendricks et al., 2000; Shaw et al., 2000). However, in humans, caffeine is generally consumed on a chronic basis. To study the effects of chronically feeding caffeine in Drosophila, we fed a low dose of caffeine over a $2 \mathrm{~d}$ period to wild-type $(R C 1)$ female flies. Figure $1 A$ shows a reduction in sleep mainly at night for flies fed 0.5 $\mathrm{mg} / \mathrm{ml}$ caffeine in constant darkness (DD). The reduction in daily sleep is dose-dependent from 0.1 to $0.5 \mathrm{mg} / \mathrm{ml}$ caffeine (Fig. $1 B$ ), and is significant for 0.2 and $0.5 \mathrm{mg} / \mathrm{ml}$ compared with no caffeine treatment. Similar results are seen over a $7 \mathrm{~d}$ period (supplemental Fig. 1, available at www.jneurosci.org as supplemental material) and also have been recently observed by Andretic et al. (2008). Analysis of sleep bout architecture reveals a significant increase in sleep bout number (Fig. 1C) and a significant decrease in sleep bout duration (Fig. $1 D$ ) in a dose-dependent manner, compared with no caffeine treatment. However, caffeine administration does not appear to make female flies hyperactive as measured by waking activity (activity/waking min) (Fig. $1 E$ ). Male flies exhibit a similar response to caffeine, except that they appear to be more sensitive to its wake-promoting effects, and sleep bout number is not elevated (supplemental Table 1, available at www.jneurosci.org as supplemental material). We also observed similar but less pronounced effects in a 12/12 h L/D cycle (supplemental Fig. 2A-D, available at www.jneurosci.org as supplemental material), and so we focused on DD behavior in subsequent experiments, which also allowed analysis of circadian behavior.

We previously showed that arousal threshold is commonly reduced during sleep in short-sleeping mutants ( $\mathrm{Wu}$ et al., 
2008). We therefore assayed whether chronic caffeine also reduces arousal threshold in flies. As shown in Figure $1 F$, flies fed $0.5 \mathrm{mg} / \mathrm{ml}$ caffeine were more likely to be aroused from sleep using a mild or moderate stimulus, compared with flies fed no caffeine. Together, these data demonstrate that chronic administration of caffeine fragments sleep and reduces arousal threshold in Drosophila.

In addition to these effects of caffeine on sleep, $0.5 \mathrm{mg} / \mathrm{ml}$ caffeine affects circadian rhythms by lengthening the period by $\sim 0.9 \mathrm{~h}$ for male flies and $\sim 0.5 \mathrm{~h}$ for female flies (Fig. 2). Like its effect on sleep, the effect of caffeine on circadian period is dose-dependent (Fig. 2B). The lengthening of the circadian period suggests caffeine also affects central clock function.

\section{The Drosophila adenosine receptor is not required for regulation of sleep} Caffeine has been proposed to promote wakefulness in mammals by antagonizing adenosine receptor activity, specifically the $\mathrm{A}_{2 \mathrm{~A}}$ subtype (Fredholm et al., 1999; Huang et al., 2005). In addition, adenosine has been proposed to function as a somnogen signaling homeostatic sleep need (Basheer et al., 2004). Therefore, the simplest model predicts that genetically eliminating adenosine signaling would result in reduced sleep or reduced sleep rebound. In mammals, there are four adenosine receptor subtypes. In contrast, there is a single adenosine receptor gene (dAdoR, CG9753) identified in Drosophila, simplifying genetic analysis (Dolezelova et al., 2007). $d A d o R$ is most closely related to the mammalian $\mathrm{A}_{2 \mathrm{~A}}$ receptor, with which it shares $52 \%$ similarity (35\% identity) over the $\mathrm{N}$-terminal region. Query of the Drosophila protein database using the human $\mathrm{A}_{2 \mathrm{~A}}$ receptor or $\mathrm{A}_{1}$ receptor identifies $d A d o R$ as the single best homolog ( $E$ values $<10^{-41}$ for $A_{2 A}$, and $<10^{-24}$ for $A_{1}$ ) with a variety of significantly less similar aminergic receptors (supplemental Tables 2, 3, available at www.jneurosci.org as supplemental material). In addition, most of the amino acids relevant for adenosine binding are conserved in $d A d o R$. Unlike other adenosine receptors, however, $d A d o R$ also has a long ( $\sim 300$ aa) cytoplasmic tail which is not conserved through evolution (Dolezelova et al., 2007).

To confirm that dAdoR responds to adenosine, we expressed dAdoR in Drosophila S2 cells and found that treatment with $3 \mu \mathrm{M}$ adenosine results in MAPK phosphorylation (Fig. 3A). Similar results were obtained by Dolezelova et al. (2007). To test the role of $d A d o R$ in sleep, we generated a $d A d o R$ deletion mutant by imprecise excision of KG03964, a P-element located $\sim 400$ bp downstream of $d A d o R$. Sequencing confirmed removal of the entire $d A d o R$ ORF, without any effect on adjacent genes. As shown by quantitative PCR analysis in Figure $3 B, d A d o R$ transcript appears to be enriched in heads versus bodies in control flies and is undetectable in the $d A d o R$ mutant. This finding is consistent with previous results (Dolezelova et al., 2007) and also the Adult Gene Expression database (Chintapalli et al., 2007). The $d A d o R$ transcript was also undetectable in flies carrying the excision allele over a deficiency of the locus, $D f(3 R)$ Exel6214 flies (data not shown).

To control for genetic background, we outcrossed $d A d o R$ mutants $5 \times$ into a wild-type background $(R C 1)$ and established sibling controls. $d A d o R$ mutants do not show a significant change in baseline daytime or nighttime sleep (Fig. 3C) in L/D, compared with background controls. Baseline sleep amount is similarly unaffected in transheterozygous $d A d o R / D f(3 R)$ Exel6214 female flies (supplemental Fig. 3A, available at www.jneurosci.org as supplemental material).

Inspection of sleep bout architecture suggests the possibility of mild sleep fragmentation. $d A d o R$ mutant flies display a significantly increased number of nighttime sleep bouts and a significant reduction in nighttime sleep bout duration, compared with controls (Fig. $3 D, E$ ). Transheterozygous $d A d o R / D f(3 R)$ Exel6214 females also exhibit reduced nighttime sleep bout duration compared with controls, but this is statistically insignificant (supplemental Fig. 3C, available at www.jneurosci.org as supplemental material). Waking activity (activity/waking minute) is not consistently altered in $d A d o R$ mutants compared with controls (supplemental Fig. 3D, available at www.jneurosci.org as supplemental material). Together, these data show that deletion of $d A d o R$ has no effect on baseline sleep amount, and subtle, if any, effects on sleep architecture.

To assess whether $d A d o R$ mutants have impaired homeostatic regulation of sleep, we examined sleep rebound following mechanical sleep deprivation (Huber et al., 2004). As shown in Figure 4, $A$ and $B, d A d o R$ mutants have similar amounts of sleep rebound compared with controls. Similar results were obtained for $d A d o R /$ $D f(3 R)$ Exel6214 flies compared with control/Df(3R)Exel6214 flies (supplemental Fig. $4 A$, available at www.jneurosci.org as supplemental material). We next examined whether $d A d o R$ mutants dis- 
A

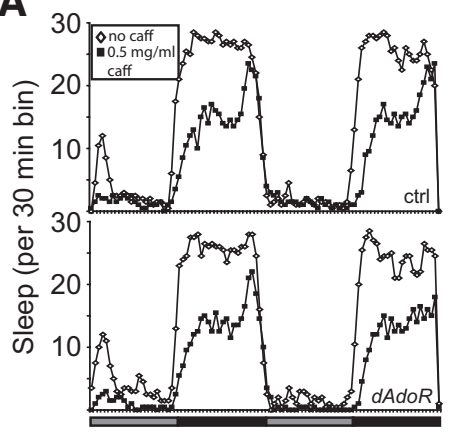

B

C

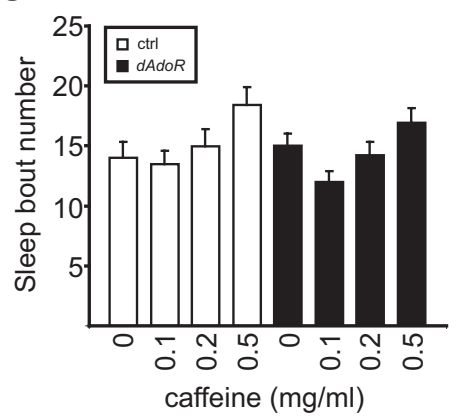

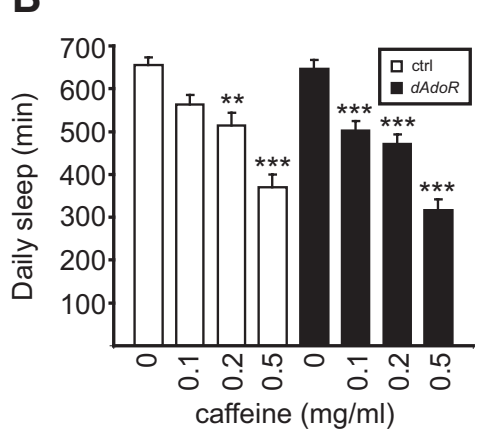

D

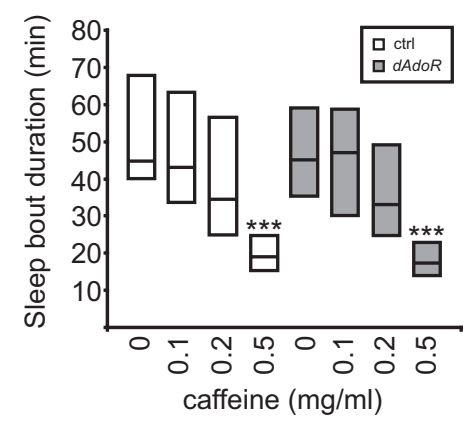

E

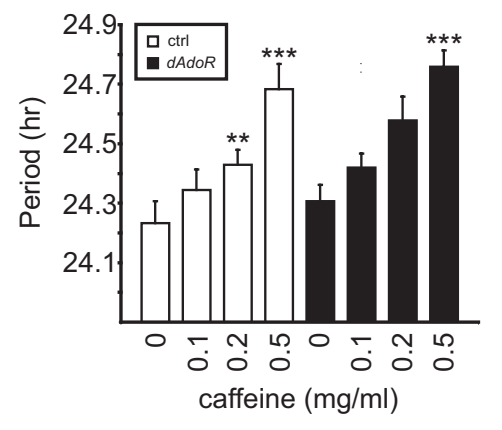

Figure 5. The effects of caffeine on sleep and circadian rhythms do not require $d A d o R$. A, Sleep profile plotted in 30 min bins for sibling control or $d A d o R$ female flies fed no caffeine (open diamonds) or $0.5 \mathrm{mg} / \mathrm{ml}$ caffeine (closed squares). Gray bars and black bars represent subjective day and night, respectively. $\boldsymbol{B}$, Daily sleep time for sibling control or $d A d o R$ female flies fed $0,0.1,0.2$, or $0.5 \mathrm{mg} / \mathrm{ml}$ caffeine. For control flies $n=28$ (no caffeine), $n=32(0.1 \mathrm{mg} / \mathrm{ml}), n=28(0.2 \mathrm{mg} / \mathrm{ml})$, and $n=32(0.5 \mathrm{mg} / \mathrm{ml})$. For dAdoRflies $n=32$ (no caffeine), $n=31(0.1 \mathrm{mg} / \mathrm{ml}), n=32(0.2 \mathrm{mg} / \mathrm{ml})$, and $n=30(0.5 \mathrm{mg} / \mathrm{ml})$. For $\boldsymbol{B}-\boldsymbol{E}$, control and $d A d o R$ are denoted with white and dark bars, respectively. $\boldsymbol{C}-\boldsymbol{E}$, Daily sleep boutnumber $(\boldsymbol{C}$, daily sleep bout duration $(\boldsymbol{D})$, and circadian period $(\boldsymbol{E})$ for sibling control or dAdoRfemale flies fed $0,0.1,0.2$, or $0.5 \mathrm{mg} / \mathrm{ml}$ caffeine. Analysis by two-factor ANOVAs revealed no interaction between genotype and caffeine dose for daily sleep, sleep bout number, sleep bout duration, or period length. There was no main effect of genotype on sleep bout number or sleep bout duration. Although there was a marginally significant main effect of genotype on daily sleep amount ( $p=0.04)$ and period length ( $p=$ 0.03 ), post hoc Tukey HSD tests did not reveal significant differences for these phenotypes between $d A d o R$ versus control flies receiving equivalent caffeine doses. In contrast, a significant main effect of caffeine dose on daily sleep, sleep bout duration, and period was observed, and significance by posthoc Tukey HSD tests is shown. ${ }^{* *} p<0.01,{ }^{* * *} p<0.001$ for caffeine-treated flies versus no caffeine treatment for a given genotype. Data for the same flies are shown for $\boldsymbol{A}-\boldsymbol{E}$. caff, Caffeine; $\boldsymbol{c t r l}$, control.

played a change in the reduction of sleep latency following sleep deprivation. We found that deletion of $d A d o R$ does not affect the reduction (\%) in sleep latency following sleep deprivation (50.9 \pm $5.8 \%$ for control vs $49.2 \pm 5.2 \%$ for $d A d o R$ mutants, $p=0.83$, and see also supplemental Fig. $4 B$, available at www.jneurosci.org as supplemental material). These data suggest that $d A d o R$ is not required for homeostatic sleep regulation in Drosophila, and together with the subtle baseline sleep phenotypes seen in $d A d o R$ mutants, suggest that $d A d o R$ is not essential for sleep regulation.

\section{The effects of caffeine on sleep and} circadian rhythms are not mediated by the adenosine receptor

It has been proposed that, in mammals, caffeine promotes wakefulness by antagonizing adenosine receptors, and $\mathrm{A}_{2 \mathrm{~A}}$ receptors in particular (Fredholm et al., 1999; Huang et al., 2005). To test the hypothesis that caffeine functions through antagonism of $d A d o R$ in Drosophila, caffeine was chronically administered to $d A d o R$ female flies. To our surprise, the effects of caffeine on sleep amount, sleep bout number, and sleep bout duration in $d A d o R$ mutant flies were similar to its effects on controls (Fig. 5A-D). Because we previously observed an increase in circadian period with chronic caffeine treatment in wild-type flies as mentioned above, we also examined circadian period in $d A d o R$ mutants following caffeine treatment. The circadian period of $d A d o R$ mutants was lengthened to a degree similar to controls (Fig. 5E). Similar results were obtained for transheterozygous $d A d o R /$ $D f(3 R)$ Exel6214 flies, compared with control/Df(3R)Exel6214 flies (supplemental Fig. $5 A, B$, available at www. jneurosci.org as supplemental material). These results suggest that the effects of caffeine on sleep and circadian rhythms are not mediated through the Drosophila adenosine receptor.

Caffeine causes widespread increase in cAMP levels, and inhibition of the PKA pathway blocks the effects of caffeine on sleep

If caffeine does not act on sleep by antagonizing $d A d o R$ signaling, how else might it act? Caffeine, like other methylated xanthines, inhibits cAMP PDE in mammalian cells, and indeed cAMP/PKA signaling is implicated in the regulation of sleep in Drosophila and mammals (Hendricks et al., 2001; Graves et al., 2003; Joiner et al., 2006). Biochemical data have suggested that the concentration of caffeine required to inhibit PDEs is higher than would be physiologically relevant in mammals (Fredholm et al., 1999), but recent data suggest that at least some of the effects of caffeine on human immune function may involve inhibition of cAMP PDE (Horrigan et al., 2006). Thus, we sought to investigate a role for the cAMP-PKA pathway in the effects of caffeine on sleep.

We first examined the effects of IBMX, a nonspecific phosphodiesterase inhibitor, and found that IBMX reduces sleep in $R C 1$ flies in a dose-dependent manner, like caffeine (Fig. 6A). Also similar to caffeine, IBMX lengthens circadian period (Fig. $6 B)$. Similar effects on sleep were obtained using other methylxanthine derivatives (supplemental Fig. $6 A, B$, available at www. jneurosci.org as supplemental material). 

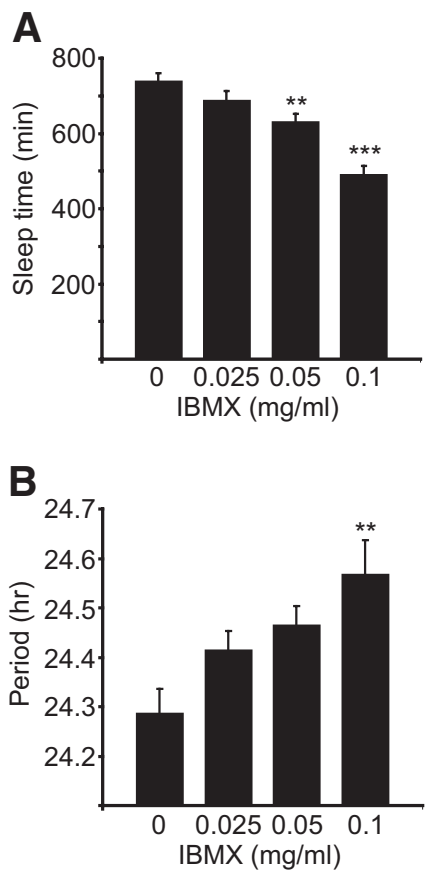

Figure 6. IBMX, a nonspecific PDE, mimics caffeine's effects on sleep and circadian rhythms. A, Daily sleep time for female flies fed $0(n=62), 0.025(n=62), 0.05(n=63)$, or $0.1(n=63)$ $\mathrm{mg} / \mathrm{ml} \mathrm{IBMX}$. B, Period (in hours) for female flies fed $0(n=28), 0.025(n=29), 0.05(n=28)$, or $0.1(n=30) \mathrm{mg} / \mathrm{ml} \mathrm{IBMX} .{ }^{* *} p<0.01,{ }^{* * *} p<0.001$ compared with diluent alone.

If caffeine acts as a cAMP PDE, one would expect the presence of caffeine to elevate cAMP levels in widespread areas throughout the fly brain. To assess this, we conducted in vivo FRET imaging with recently described UAS-Epac1-camps flies, which can be used to overexpress Epac1-camps, a FRET-based cAMP sensor (Nikolaev et al., 2004; Shafer et al., 2008). In this system, the presence of cAMP causes a reduction in FRET from donor (CFP) to recipient (YFP) chromophores. In brains where Epac1-camps is expressed pan-neuronally, we find that addition of caffeine leads to an increase in cAMP levels (as measured by a decrease in YFP/CFP signal) in widespread areas throughout the brain, including areas previously implicated in sleep regulation such as mushroom bodies (Joiner et al., 2006; Pitman et al., 2006) and pars intercerebralis (Foltenyi et al., 2007) (Fig. 7A).

To further examine whether cAMP/PKA signaling is specifically required for the effects of caffeine on sleep in flies, we used the UAS-Geneswitch system to inducibly overexpress PKAR (a regulatory subunit that inhibits cAMP signaling) pan-neuronally (Li et al., 1995; White et al., 2001). As shown in Figure 7, B and $C$, induction of PKAR expression pan-neuronally using elavGeneswitch (elav-GS) causes an increase in sleep, as predicted from published wake-promoting effects of cAMP/PKA signaling (Joiner et al., 2006). If PKAR is uninduced, treatment with 0.5 $\mathrm{mg} / \mathrm{ml}$ caffeine results in a significant reduction in sleep. However, simultaneous induction of PKAR with caffeine treatment completely suppresses the effects of caffeine on sleep (Fig. $7 B, C$ ). This effect is specific, because it is not observed when the elav-GS driver alone is used or if the Mushroom body-Geneswitch driver is crossed to UAS-PKAR (Fig. 7C). Together, these data suggest that PKA activity is required for the effects of caffeine on sleep. Given that pan-neuronal expression of PKAR blocks the effects of caffeine on sleep and that caffeine elevates cAMP levels in widespread areas throughout the fly brain, these data suggest the possibility that caffeine activates cAMP/PKA signaling in multiple brain regions to regulate sleep.

\section{Discussion}

A large body of experimental work implicates adenosine as a key regulator of sleep (Basheer et al., 2004). In addition, since sleep is thought to play a restorative role in brain energy metabolism, adenosine, as a metabolic byproduct, is a particularly attractive candidate to act as the homeostatic signal for sleep (Benington and Heller, 1995). However, the precise mechanisms by which adenosine exerts its somnogenic activity remain unclear. Much of the evidence for a sleep-promoting role of adenosine comes from pharmacological studies (Porkka-Heiskanen et al., 2002), but a variety of physiological substrates can, like adenosine, induce sleep (Ueno et al., 1983; Krueger et al., 1984, 2008; Shoham et al., 1987; Kovalzon and Strekalova, 2006).

Genetic analyses may assist in identifying the mechanisms by which adenosine acts to regulate sleep in vivo. To this end, mutants of candidate adenosine receptors have been examined for sleep phenotypes. However, deletion of the $A_{1}$ receptor in mice does not significantly alter baseline or homeostatic regulation of sleep (Stenberg et al., 2003). Furthermore, $A_{2 A}$ knock-out mice have normal amounts of baseline sleep, and there are no published data describing the homeostatic response of these mice to sleep deprivation (Huang et al., 2005). The absence of dramatic effects on sleep regulation in $\mathrm{A}_{1}$ and $\mathrm{A}_{2 \mathrm{~A}}$ knock-out mice could be attributed to developmental compensation or genetic redundancy, which ultimately could be addressed with double knock outs or temporally regulated knock outs. Along these lines, Bjorness et al. (2009) show that conditional knock out of the $A_{1}$ adenosine receptor in mice results in attenuated SWA power at baseline and following sleep deprivation (Bjorness et al., 2009). In addition, double $A_{1} / A_{2 A}$ knock-out mice have been described (Halldner et al., 2004), and it would be interesting to study the sleep phenotype in these animals.

Genetic analysis in fruitflies is typically less encumbered by problems of compensation or redundancy. For instance, sequence analysis predicts only a single adenosine receptor, and we and others find that this receptor responds to adenosine (Dolezelova et al., 2007). We generated a deletion mutant eliminating $d A d o R$ and find that mutants lacking $d A d o R$ do not exhibit clear changes in either baseline sleep or homeostatic regulation of sleep following sleep deprivation. These data are compatible with previous genetic studies of $\mathrm{A}_{1}$ and $\mathrm{A}_{2 \mathrm{~A}}$ knock outs in mice (Stenberg et al., 2003; Huang et al., 2005). However, there are several potential caveats. First, we cannot exclude the possibility that another unknown, and significantly less related, receptor responds to adenosine in Drosophila. Second, unlike changes in SWA power in mammals, changes in the depth of sleep cannot be strictly evaluated in our system, so we cannot rule out the possibility that the quality of sleep is altered in $d A d o R$ flies. Along these lines, there is a hint that sleep maintenance may be slightly disturbed in $d A d o R$ mutants. Third, there remains the possibility that loss of $d A d o R$ can be developmentally compensated. The last two points are underscored by the recent observation that conditional knock out of the $A_{1}$ adenosine receptor in mice results in attenuated SWA power at baseline and following sleep deprivation (Bjorness et al., 2009). Together with the large body of experimental work implicating adenosine in sleep regulation, these data suggest that, although adenosine almost certainly can modulate sleep (and slow wave sleep in particular), signaling through adenosine receptors is not absolutely essential for regulation of sleep amount or need. 
A

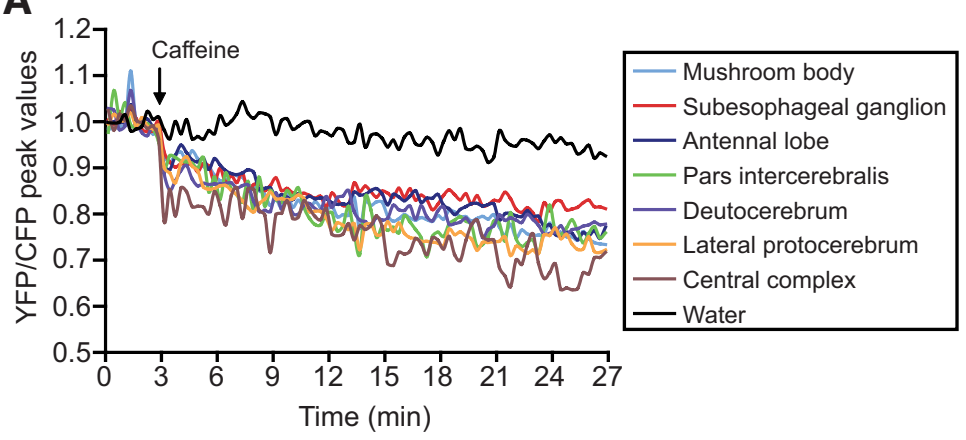

B
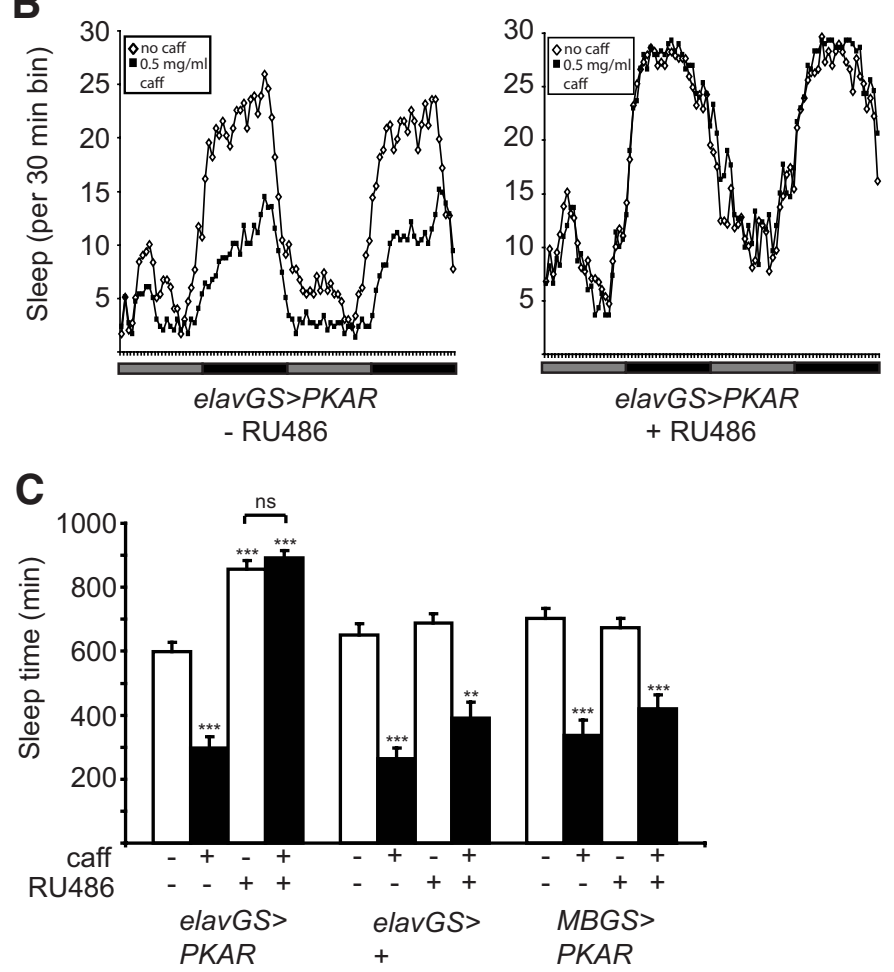

Figure 7. cAMP/PKA signaling is required for the effects of caffeine on sleep. $A$, Caffeine reduces Epac1-camps FRET. Average FRET plots, as measured by YFP/CFP peak signals, for different regions of interest (ROI) following bath application of $0.375 \mathrm{mg} / \mathrm{ml}$ caffeine on elav-Gal4/+; UAS-Epac1-camps/+ brains. Decreasing YFP/CFP reflects increasing cAMP levels. Arrow represents the start of caffeine exposure. For each ROl, the following number of brains were analyzed as follows: mushroom body $(n=7)$, subesophageal ganglion $(n=8)$, antennal lobe $(n=6)$, pars intercerebralis $(n=3)$, deutocerebrum $(n=6)$, lateral protocerebrum $(n=4)$, central complex $(n=2)$. The brain ROIs in the five water-treated brains were pooled. YFP/CFP peak signals pooled in 6 min bins were statistically different from water (at least $p<0.05$ ) in all regions and all bins, except central complex, which was statistically different only for minutes $21-27$, and subesophageal ganglion, which was statistically similar for minutes $15-21$. B, Sleep profile in $30 \mathrm{~min}$ bins is shown for uninduced (left panel) or induced (right panel) elav-GS $\times$ UAS-PKAR female flies that were fed no caffeine (open diamonds) or $0.5 \mathrm{mg} / \mathrm{ml}$ caffeine (closed squares) as indicated. Dark bars and gray bars indicate subjective nighttime and daytime, respectively. C, Daily sleep time for elav-GS $\times$ UAS-PKAR $(n=45-47)$, elav-GS $\times$ control background $(n=15-16)$, or MB-GS $\times$ UAS-PKAR $(n=17-18)$ female flies. Flies were treated with $0.5 \mathrm{mg} / \mathrm{ml}$ caffeine and/or $0.5 \mathrm{~mm}$ RU486 as indicated. ${ }^{* *} p<0.01$, ${ }^{* * *} p<0.001$ compared with "- caffeine - RU486" of the same genotype. "ns" signifies a nonsignificant difference. caff, Caffeine.

Caffeine, one of the most widely used psychostimulants, is believed to promote wakefulness by antagonizing adenosine receptor function, although at higher doses it can inhibit cAMP PDE (Fredholm et al., 1999). In mammals, it seems very likely that the increase in locomotor activity induced by lower doses of caffeine is mediated by the $\mathrm{A}_{2 \mathrm{~A}}$ receptor (Ledent et al., 1997; El Yacoubi et al., 2000; Halldner et al., 2004), and indeed the $A_{2 A}$ receptor is specifically enriched in the basal ganglia, a structure particularly important for control of motor activity. Furthermore, additional results suggest that in mice, $A_{2 A}$, but not $A_{1}$ receptors, are required for the acute wakepromoting effects of caffeine (Huang et al., 2005).

We show here that chronic administration of caffeine reduces and fragments sleep in Drosophila. Caffeine also appears to impact the central clock, since we find caffeine administration lengthens circadian period, a finding which has also been observed in Neurospora (Feldman, 1975). However, we were surprised to find that chronic caffeine treatment had similar effects on sleep and circadian rhythms in $d A d o R$ mutants and controls. How do we reconcile the discrepancy between our findings and the $\mathrm{A}_{2 \mathrm{~A}}$ knock-out data? One possibility is that acute versus chronic exposure to caffeine involves different mechanisms (Jacobson et al., 1996). For instance, many of the studies describing the blockade of locomotor stimulation in $\mathrm{A}_{2 \mathrm{~A}}$ knock-out mice in response to caffeine use a single bolus of caffeine (Ledent et al., 1997; El Yacoubi et al., 2000; Halldner et al., 2004; Huang et al., 2005), whereas in this study we feed flies caffeine chronically. Another possibility is that fundamentally different signaling mechanisms regarding adenosine and caffeine are used in mammals versus flies. Although the latter explanation cannot be ruled out, the conservation of multiple signaling pathways underlying sleep between flies and other model systems argues against this possibility (Wisor et al., 2001; Ursin, 2002; Siegel, 2004; Kume et al., 2005; Yuan et al., 2006; Allada and Siegel, 2008; Crocker and Sehgal, 2008; Zimmerman et al., 2008).

In addition to antagonizing adenosine signaling, is there another potential mechanism of action for caffeine? Similar to the effects of caffeine, we observe a significant reduction in sleep and increase in circadian period length when we feed IBMX, a nonspecific phosphodiesterase inhibitor, to flies. Furthermore, using FRET imaging of fly brains, we find that addition of caffeine results in elevation of cAMP levels in widespread areas in the fly brain, including areas previously implicated in sleep regulation. Finally, we find that blocking PKA signaling pan-neuronally in wild-type flies suppresses the effects of chronic caffeine on sleep. Interestingly, the Drosophila D1 dopamine receptor is required for the effect of caffeine on sleep, and this effect can be rescued by overexpression of D1 in mushroom bodies (Andretic et al., 2008). Together with our data, it is possible that dopamine signaling in mushroom bodies acts downstream of widespread cAMP/PKA signaling induced by caffeine. 
We and others have shown that cAMP/PKA signaling is important for promoting wakefulness in flies and mice (Hendricks et al., 2001; Graves et al., 2003; Joiner et al., 2006). Given its previously defined activity as a cAMP PDE inhibitor and the effect we report here on cAMP levels, we suggest that caffeine promotes wakefulness by enhancing cAMP levels. Along these lines, caffeine can inhibit cAMP PDE activity in Drosophila, and it induces specific cytochrome genes in flies via suppression of PDE activity independent of $d A d o R$ signaling (Bhaskara et al., 2008). Furthermore, in human lymphocytes, caffeine, at physiologically relevant doses, appears to act through PDE to modulate immune function (Horrigan et al., 2006). Thus, we suggest that, in Drosophila, chronic effects of caffeine on sleep/wake regulation may be mediated, at least in part, by PDE inhibition. Further genetic studies of adenosine receptor mutants and PKA signaling in flies and mammals will be of benefit in elucidating the precise roles of adenosine and caffeine in sleep regulation.

\section{References}

Allada R, Siegel JM (2008) Unearthing the phylogenetic roots of sleep. Curr Biol 18:R670-R679.

Andretic R, Shaw PJ (2005) Essentials of sleep recordings in Drosophila: moving beyond sleep time. Methods Enzymol 393:759-772.

Andretic R, Kim YC, Jones FS, Han KA, Greenspan RJ (2008) Drosophila D1 dopamine receptor mediates caffeine-induced arousal. Proc Natl Acad Sci U S A 105:20392-20397.

Basheer R, Strecker RE, Thakkar MM, McCarley RW (2004) Adenosine and sleep-wake regulation. Prog Neurobiol 73:379-396.

Benington JH, Heller HC (1995) Restoration of brain energy metabolism as the function of sleep. Prog Neurobiol 45:347-360.

Benington JH, Kodali SK, Heller HC (1995) Stimulation of A1 adenosine receptors mimics the electroencephalographic effects of sleep deprivation. Brain Res 692:79-85.

Bhaskara S, Chandrasekharan MB, Ganguly R (2008) Caffeine induction of Cyp6a2 and Cyp6a8 genes of Drosophila melanogaster is modulated by cAMP and D-JUN protein levels. Gene 415:49-59.

Bjorness TE, Kelly CL, Gao T, Poffenberger V, Greene RW (2009) Control and function of the homeostatic sleep response by adenosine A1 receptors. J Neurosci 29:1267-1276.

Blanco-Centurion C, Xu M, Murillo-Rodriguez E, Gerashchenko D, Shiromani AM, Salin-Pascual RJ, Hof PR, Shiromani PJ (2006) Adenosine and sleep homeostasis in the basal forebrain. J Neurosci 26:8092-8100.

Chintapalli VR, Wang J, Dow JA (2007) Using FlyAtlas to identify better Drosophila melanogaster models of human disease. Nat Genet 39: 715-720.

Crocker A, Sehgal A (2008) Octopamine regulates sleep in Drosophila through PKA-dependent mechanisms. J Neurosci 28:9377-9385.

Dolezelova E, Nothacker HP, Civelli O, Bryant PJ, Zurovec M (2007) A Drosophila adenosine receptor activates cAMP and calcium signaling. Insect Biochem Mol Biol 37:318-329.

El Yacoubi M, Ledent C, Ménard JF, Parmentier M, Costentin J, Vaugeois JM (2000) The stimulant effects of caffeine on locomotor behaviour in mice are mediated through its blockade of adenosine $\mathrm{A}(2 \mathrm{~A})$ receptors. $\mathrm{Br} \mathrm{J}$ Pharmacol 129:1465-1473.

Feldman JF (1975) Circadian periodicity a Neurospora: alteration by inhibitors of cyclic AMP phosphodiesterase. Science 190:789-790.

Foltenyi K, Greenspan RJ, Newport JW (2007) Activation of EGFR and ERK by rhomboid signaling regulates the consolidation and maintenance of sleep in Drosophila. Nat Neurosci 10:1160-1167.

Fredholm BB, Bättig K, Holmén J, Nehlig A, Zvartau EE (1999) Actions of caffeine in the brain with special reference to factors that contribute to its widespread use. Pharmacol Rev 51:83-133.

Graves LA, Hellman K, Veasey S, Blendy JA, Pack AI, Abel T (2003) Genetic evidence for a role of CREB in sustained cortical arousal. J Neurophysiol 90:1152-1159.

Halldner L, Adén U, Dahlberg V, Johansson B, Ledent C, Fredholm BB (2004) The adenosine A1 receptor contributes to the stimulatory, but not the inhibitory effect of caffeine on locomotion: a study in mice lacking adenosine A1 and/or A2A receptors. Neuropharmacology 46:1008-1017.

Hendricks JC, Finn SM, Panckeri KA, Chavkin J, Williams JA, Sehgal A, Pack AI (2000) Rest in Drosophila is a sleep-like state. Neuron 25:129-138.

Hendricks JC, Williams JA, Panckeri K, Kirk D, Tello M, Yin JC, Sehgal A (2001) A non-circadian role for cAMP signaling and CREB activity in Drosophila rest homeostasis. Nat Neurosci 4:1108-1115.

Ho KS, Sehgal A (2005) Drosophila melanogaster: an insect model for fundamental studies of sleep. Methods Enzymol 393:772-793.

Horrigan LA, Kelly JP, Connor TJ (2006) Immunomodulatory effects of caffeine: friend or foe? Pharmacol Ther 111:877-892.

Huang ZL, Qu WM, Eguchi N, Chen JF, Schwarzschild MA, Fredholm BB, Urade $\mathrm{Y}$, Hayaishi O (2005) Adenosine A(2A), but not A(1), receptors mediate the arousal effect of caffeine. Nat Neurosci 8:858-859.

Huang ZL, Urade Y, Hayaishi O (2007) Prostaglandins and adenosine in the regulation of sleep and wakefulness. Curr Opin Pharmacol 7:33-38.

Huber R, Hill SL, Holladay C, Biesiadecki M, Tononi G, Cirelli C (2004) Sleep homeostasis in Drosophila melanogaster. Sleep 27:628-639.

Jacobson KA, von Lubitz DK, Daly JW, Fredholm BB (1996) Adenosine receptor ligands: differences with acute versus chronic treatment. Trends Pharmacol Sci 17:108-113.

Joiner WJ, Crocker A, White BH, Sehgal A (2006) Sleep in Drosophila is regulated by adult mushroom bodies. Nature 441:757-760.

Kovalzon VM, Strekalova TV (2006) Delta sleep-inducing peptide (DSIP): a still unresolved riddle. J Neurochem 97:303-309.

Krueger JM (2008) The role of cytokines in sleep regulation. Curr Pharm Des 14:3408-3416.

Krueger JM, Walter J, Dinarello CA, Wolff SM, Chedid L (1984) Sleeppromoting effects of endogenous pyrogen (interleukin-1). Am J Physiol 246:R994-R999.

Kume K, Kume S, Park SK, Hirsh J, Jackson FR (2005) Dopamine is a regulator of arousal in the fruit fly. J Neurosci 25:7377-7384.

Landolt HP (2008) Sleep homeostasis: a role for adenosine in humans? Biochem Pharmacol 75:2070-2079.

Ledent C, Vaugeois JM, Schiffmann SN, Pedrazzini T, El Yacoubi M, Vanderhaeghen JJ, Costentin J, Heath JK, Vassart G, Parmentier M (1997) Aggressiveness, hypoalgesia and high blood pressure in mice lacking the adenosine A2a receptor. Nature 388:674-678.

Li W, Ohlmeyer JT, Lane ME, Kalderon D (1995) Function of protein kinase A in hedgehog signal transduction and Drosophila imaginal disc development. Cell 80:553-562.

Methippara MM, Kumar S, Alam MN, Szymusiak R, McGinty D (2005) Effects on sleep of microdialysis of adenosine $\mathrm{A} 1$ and $\mathrm{A} 2 \mathrm{a}$ receptor analogs into the lateral preoptic area of rats. Am J Physiol Regul Integr Comp Physiol 289:R1715-R1723.

Nikolaev VO, Bünemann M, Hein L, Hannawacker A, Lohse MJ (2004) Novel single chain cAMP sensors for receptor-induced signal propagation. J Biol Chem 279:37215-37218.

Pitman JL, McGill JJ, Keegan KP, Allada R (2006) A dynamic role for the mushroom bodies in promoting sleep in Drosophila. Nature 441:753-756.

Porkka-Heiskanen T, Strecker RE, Thakkar M, Bjorkum AA, Greene RW, McCarley RW (1997) Adenosine: a mediator of the sleep-inducing effects of prolonged wakefulness. Science 276:1265-1268.

Porkka-Heiskanen T, Alanko L, Kalinchuk A, Stenberg D (2002) Adenosine and sleep. Sleep Med Rev 6:321-332.

Portas CM, Thakkar M, Rainnie DG, Greene RW, McCarley RW (1997) Role of adenosine in behavioral state modulation: a microdialysis study in the freely moving cat. Neuroscience 79:225-235.

Radulovacki M, Virus RM, Djuricic-Nedelson M, Green RD (1984) Adenosine analogs and sleep in rats. J Pharmacol Exp Ther 228:268-274.

Rainnie DG, Grunze HC, McCarley RW, Greene RW (1994) Adenosine inhibition of mesopontine cholinergic neurons: implications for EEG arousal. Science 263:689-692.

Shafer OT, Kim DJ, Dunbar-Yaffe R, Nikolaev VO, Lohse MJ, Taghert PH (2008) Widespread receptivity to neuropeptide PDF throughout the neuronal circadian clock network of Drosophila revealed by real-time cyclic AMP imaging. Neuron 58:223-237.

Shaw PJ, Cirelli C, Greenspan RJ, Tononi G (2000) Correlates of sleep and waking in Drosophila melanogaster. Science 287:1834-1837. 
Shoham S, Davenne D, Cady AB, Dinarello CA, Krueger JM (1987) Recombinant tumor necrosis factor and interleukin 1 enhance slow-wave sleep. Am J Physiol 253:R142-R149.

Siegel JM (2004) The neurotransmitters of sleep. J Clin Psychiatry 65 [Supp] 16]4-7.

Stenberg D, Litonius E, Halldner L, Johansson B, Fredholm BB, PorkkaHeiskanen T (2003) Sleep and its homeostatic regulation in mice lacking the adenosine A1 receptor. J Sleep Res 12:283-290.

Thakkar MM, Winston S, McCarley RW (2003) $A_{1}$ receptor and adenosinergic homeostatic regulation of sleep-wakefulness: effects of antisense to the $A_{1}$ receptor in the cholinergic basal forebrain. J Neurosci 23:4278-4287.

Ueno R, Honda K, Inoué S, Hayaishi O (1983) Prostaglandin D2, a cerebral sleep-inducing substance in rats. Proc Natl Acad Sci U S A 80:1735-1737.

Ursin R (2002) Serotonin and sleep. Sleep Med Rev 6:55-69.
White B, Osterwalder T, Keshishian H (2001) Molecular genetic approaches to the targeted suppression of neuronal activity. Curr Biol 11:R1041-R1053.

Wisor JP, Nishino S, Sora I, Uhl GH, Mignot E, Edgar DM (2001) Dopaminergic role in stimulant-induced wakefulness. J Neurosci 21:1787-1794.

Wu MN, Koh K, Yue Z, Joiner WJ, Sehgal A (2008) A genetic screen for sleep and circadian mutants reveals mechanisms underlying regulation of sleep in Drosophila. Sleep 31:465-472.

Yuan Q, Joiner WJ, Sehgal A (2006) A sleep-promoting role for the Drosophila serotonin receptor 1A. Curr Biol 16:1051-1062.

Zheng X, Yang Z, Yue Z, Alvarez JD, Sehgal A (2007) FOXO and insulin signaling regulate sensitivity of the circadian clock to oxidative stress. Proc Natl Acad Sci U S A 104:15899-15904.

Zimmerman JE, Naidoo N, Raizen DM, Pack AI (2008) Conservation of sleep: insights from non-mammalian model systems. Trends Neurosci 31:371-376. 